\title{
ANTISSÉPTICOS BUCAIS PRÉ-PROCEDIMENTO COMO PREVENÇÃO AO SARS-COV-2 EM ODONTOLOGIA: REVISÃO INTEGRATIVA
}

\author{
Victória Escóssia Germano ${ }^{\prime}$ \\ *Louise Helena de Freitas Ribeiro II
}

\section{RESUMO}

O SARS-CoV-2 e a pandemia da COVID-19 destacaram os riscos biológicos aos quais a equipe odontológica está exposta bem como a necessidade da adoção de medidas de biossegurança para diminuir a possibilidade de contaminação no ambiente odontológico. Uma das recomendações para reduzir o risco de transmissão viral é o uso de antissépticos bucais pelos pacientes antes dos atendimentos odontológicos. Esta revisão de literatura tem o objetivo de analisar as informações disponíveis a respeito do uso dos antissépticos bucais na Odontologia e a possível atividade dessas soluções contra o novo coronavírus. Para esta revisão integrativa foram selecionadas publicações científicas nas bases de dados eletrônicas Science Direct, Google Acadêmico, Scielo e PubMed, que abrangessem os temas SARS-CoV-2 e antissépticos bucais recomendados para bochecho pré-procedimento. Os resultados da revisão evidenciam que os antissépticos bucais são empregados na Odontologia para reduzir a quantidade de microrganismos, tratamento de doenças gengivais e periodontais, controle de placa bacteriana e profilaxia contra infecções. Ainda não há estudos clínicos que comprovem eficácia de enxaguantes bucais pré-procedimento na redução da carga viral ou prevenção de transmissão do SARS-CoV-2. No entanto, a realização de bochechos pré-procedimentos odontológicos é recomendada por organizações e associações de referência em saúde. Em vista disso, se faz necessária a realização de estudos clínicos randomizados que comprovem a efetividade do uso dos antissépticos bucais contra o SARS-CoV-2.

PALAVRAS-CHAVE: Odontologia. SARS-CoV-2. Peróxido de Hidrogênio. Clorexidina. Povidona-lodo.

Graduanda, Faculdade de Enfermagem Nova Esperança de Mossoró, FACENE/RN. Departamento de I Odontologia . CEP: 59.628-000, Mossoró, Rio Grande do Norte, Brasil.

ORCID ID: 0000-0001-7479-5297.

Mestra em Biotecnologia de Recursos Naturais. Docente, Faculdade de Enfermagem Nova Esperança de Mossoró, FACENE/RN. Departamento de Odontologia . CEP: 59.628-000, Mossoró, Rio Grande do Norte, Brasil. *Autor correspondente: louise@facenemossoro.com.br ORCID ID: 0000-0002-8729-013X. 


\section{INTRODUÇÃO}

Profissionais da área odontológica e pacientes estão em constante risco de exposição a diversos microrganismos patogênicos que infectam a cavidade oral e o trato respiratório, entre eles o SARSCoV-2. Os procedimentos de atendimento odontológico proporcionam elevado risco de contaminação, devido à sua especificidade, ao mesmo tempo que expõem o profissional ao contato direto com pacientes possivelmente infectados. A exemplo de: contato com a saliva, sangue e outros fluidos corporais; ao contato da mucosa conjuntival, nasal ou oral com microrganismos presentes em gotículas e aerossóis; ao manuseio de instrumentos perfurocortantes e ao contato indireto com objetos e/ou superfícies contaminadas. ${ }^{1,2}$

Os enxaguantes bucais antissépticos são comumente empregados na odontologia como forma de tratamento de doenças gengivais e periodontais, controle químico de placa bacteriana, prevenção de halitose e profilaxia contra infecções, após procedimentos cirúrgicos intraorais. Seu espectro de ação é consideravelmente mais amplo que o dos antibióticos, atuando contra bactérias, fungos, leveduras e vírus.

\section{MATERIAL E MÉTODOS}

Para a revisão integrativa, foram pesquisados artigos científicos nas bases de dados eletrônicas Science Direct, Google Acadêmico, Scielo e PubMed no período de agosto a outubro de 2020. A pesquisa foi direcionada a publicações gerais sobre o SARSCoV-2, os antissépticos bucais recomendados para bochecho pré-procedimento empregados na Odontologia, e a relação entre o uso de
O mecanismo de ação dessas substâncias pode ter como alvo membranas celulares de microrganismos, envelopes lipídicos virais e ácidos nucleicos. ${ }^{3}$

A utilização do bochecho préprocedimento com soluções antissépticas como um meio de reduzir a possível carga viral do SARS-CoV-2 e, consequentemente, diminuir o risco de transmissão do vírus é uma das medidas recomendadas por diversas associações e órgãos de saúde, como a Organização Mundial da Saúde (OMS), o Centro de Controle e Prevenção de Doenças (CDC), a Associação Dental Americana (ADA) e o Conselho Federal de Odontologia (CFO). Apesar dessa recomendação, não há evidência científica baseada em estudos clínicos que comprovem a efetividade do uso dos antissépticos bucais para redução da carga viral ou prevenção de transmissão do SARSCoV-2. 4,5,6,7

Em vista disso, esta revisão de literatura tem o objetivo de analisar as informações disponíveis a respeito do uso dos antissépticos bucais na Odontologia e a possível atividade dessas soluções contra o novo coronavírus. antissépticos bucais e a redução de carga viral do SARS-CoV-2.

Os seguintes termos, contidos nos Descritores em Ciências da Saúde - DeCS, em língua inglesa e portuguesa, foram escolhidos para a busca e organizados, através de operadores booleanos: SARSCoV-2* AND Mouthwashes*; SARS-CoV-2* AND Mouthwashes* AND Hydrogen 
peroxide*; SARS-CoV-2* AND Mouthwashes* AND Chlorhexidine*; SARS-CoV-2* AND Mouthwashes* AND lodopovidone*. Dos 59 artigos encontrados, foram selecionados 22 trabalhos publicados entre 1997 e 2020, de acordo com a publicação mais recente sobre o tema.

Como critério de inclusão, foram adotadas publicações que abordaram os temas "SARS-CoV-2", "biossegurança" e "uso de antissépticos bucais e atividade virucida das soluções antissépticas". Excluíram-se estudos não pertinentes a temática escolhida

\section{RESULTADOS E DISCUSSÃO}

\section{O novo coronavírus e a pandemia da COVID-19}

Em 31 de dezembro de 2019, autoridades de saúde da cidade de Wuhan, na China, reportaram diversos casos de indivíduos recebendo tratamento para uma pneumonia viral de causa desconhecida. Em 9 de janeiro de 2020, foi determinado que essa síndrome respiratória era causada por uma nova espécie de coronavírus, o SARS-CoV-2. ${ }^{8}$

O SARS-CoV-2 (Coronavírus da Síndrome Respiratória Aguda Grave 2) pertencea ordem dos Nidovirales, que possuem invólucro lipídico e genoma constituído de RNA de cadeia não segmentada, simples e de sentido positivo [(+) ssRNA]. Dentro dessa ordem está a família e subfamília Coronaviridae, constituída pelos gêneros $\alpha-\mathrm{CoV}, \beta-\mathrm{CoV}, \gamma-\mathrm{CoV}$ e $\delta$-CoV. A análise filogenética do SARS-CoV-2 mostrou que esse espécime está incluso no gênero $\beta-\mathrm{CoV}$, assim como o Coronavírus da Síndrome Respiratória Aguda Grave (SARSCoV) e o Coronavírus da Síndrome Respiratória do Oriente Médio (MERS-CoV). ${ }^{1,9}$

O novo coronavírus utiliza como principal receptor de ligação e porta de e artigos sobre soluções antissépticas a base de cloreto de cetilpiridínio e óleos essenciais, devido ao fato de essas soluções serem recomendadas somente nas diretrizes do Centro de Controle e Prevenção de Doenças (CDC) e não mencionadas pelas demais.

Também foram incluídas nessa revisão diretrizes e recomendações das seguintes organizações e associações de referência em saúde: Organização Mundial da Saúde (OMS), Centro de Controle e Prevenção de Doenças (CDC), Associação Dental Americana (ADA) e Conselho Federal de Odontologia (CFO).

entrada na célula a ACE2 (Enzima Conversora de Angiotensina 2), que é expressa tanto no epitélio do trato respiratório quanto no epitélio dos ductos das glândulas salivares. Dessa forma, a carga viral é mais elevada na cavidade nasal, nasofaringe e orofaringe e consistentemente alta na saliva, o que faz a sua transmissão ocorrer principalmente por contato direto ou indireto com gotículas respiratórias geradas por espirro, tosse, respiração ou conversa. ${ }^{1,10,11}$

Diversos casos e mortes relacionadas a infecção por SARS-CoV-2 foram contabilizadas ao redor do globo, de modo que, em 11 de março de 2020, devido aos níveis preocupantes de propagação e gravidade da doença e de inação por parte dos governos e sociedade, a OMS caracterizou a COVID-19 como uma pandemia. Foi recomendado que os países adotassem uma abordagem desenvolvida em torno de uma estratégia abrangente para prevenir infecções, salvar vidas e minimizar o impacto da doença, envolvendo ações de todos os governos e sociedade, sendo assim preconizadas medidas de isolamento 
e biossegurança como forma de conter o avanço do vírus. 8

No entanto, o SARS-CoV-2 continuou a se disseminar em uma proporção alarmante e outros países tornaram-se epicentros da doença. Depois da China, o número de casos cresceu na Coréia do Sul, Itália, Espanha, Estados Unidos, Brasil e Índia. Em 4 de abril de 2020, já haviam sido confirmados 1 milhão de casos de COVID-19, e até o dia 03 de dezembro de 2020, foram reportados pela OMS 63.965.092 casos confirmados e 1.488 .120 mortes em todo o mundo. ${ }^{12}$

\section{Contaminação no ambiente odontológico}

$\mathrm{Na}$ prática odontológica, o preparo dental com instrumentos rotatórios, a remoção de cálculo dental com aparelhos ultrassônicos, o uso de dispositivos de abrasão a ar e de seringa tríplice podem gerar respingos e aerossóis que, além de gotículas de água, são compostos de resquícios de saliva, secreções orofaríngeas, sangue, detritos e microrganismos. 2,6

Em virtude do grande risco de contaminação a qual está exposta a equipe odontológica, torna-se imprescindível a adoção de medidas de biossegurança para minimizar as possibilidades de contágio. Entre essas medidas estão: usar equipamento de proteção individual (EPI), como luvas, óculos de proteção, respirador PFF2 ou N95, máscara cirúrgica e protetor facial; fornecer ao paciente uma solução antisséptica para bochecho antes do procedimento clínico; optar por técnicas minimamente invasivas; evitar procedimentos geradores de aerossóis; realizar a desinfecção do ambiente a cada paciente; e utilizar sugadores de alta potência. 2,6

\section{Antissépticos bucais e seu uso na Odontologia}

Antisséptico é qualquer agente que, quando aplicado em tecidos vivos, é capaz de prevenir ou interromper o crescimento ou ação de microrganismos. Seu espectro de ação é consideravelmente mais amplo que o dos antibióticos e muitas vezes possuem vários alvos intracelulares, o que reduz a probabilidade do desenvolvimento de resistência microbiana. Apesar da eficácia apresentada, sua utilização em humanos é limitada a feridas infectadas, pele e mucosa, uma vez que são potencialmente tóxicos não apenas para agentes infecciosos, mas também para as células do hospedeiro. 3

Os enxaguantes bucais antissépticos são bastante empregados na Odontologia como forma de tratamento de doenças gengivais e periodontais, controle químico de placa bacteriana, prevenção de halitose e profilaxia contra infecções orais pósexodontias, após procedimentos cirúrgicos intraorais ou imunossupressão, devido a terapia de câncer ou transplante. 3

Ainda não há estudos clínicos que comprovem efetividade de enxaguantes bucais pré-procedimento na redução da carga viral, ou prevenção de transmissão do SARSCoV-2. No entanto, a realização de bochechos com soluções antissépticas antes dos procedimentos odontológicos é largamente recomendada (ADA, 2020, CDC, 2020). A Associação Dental Americana, por exemplo, recomenda o uso de peróxido de hidrogênio a $1,5 \%$ ou iodopovidona a $0,2 \%$ como enxaguante bucal antes do procedimento odontológico. 5

O Centro de Controle e Prevenção de Doenças $(C D C)$ recomenda a utilização de enxaguantes bucais com agentes antimicrobianos como digluconato de clorexidina, óleos essenciais, iodopovidona e cloreto de cetilpiridínio, para reduzir o nível de microrganismos orais em aerossóis e gotículas geradas em procedimentos dentais. 5

O Conselho Federal de Odontologia (CFO), em conjunto com a Associação de 
Medicina Intensiva Brasileira (AMIB) e a Organização Mundial da Saúde (OMS), sugere que o profissional forneça ao paciente uma solução de peróxido de hidrogênio a $1 \%$ para bochecho antes de cada atendimento.4,7 A OMS ainda propõe o bochecho com iodopovidona a $0,2 \%$ durante 20 segundos antes de iniciar exame clínico, ou qualquer procedimento, com o objetivo de reduzir a carga salivar de micróbios orais, incluindo SARS-CoV-2.4 O enxágue bucal com a clorexidina não é recomendado pelo CFO, por esta solução ser ineficaz contra a COVID-19.7

Em uma breve revisão de literatura, Vergara-Buenaventura e Castro-Ruiz (2020) sugerem que o bochecho pré-procedimento seja realizado por 30 segundos na cavidade bucal e 30 segundos na porção posterior da garganta. Entre as soluções antissépticas propostas estão: $15 \mathrm{ml}$ de peróxido de hidrogênio a 1,5\% ou 3\%; $9 \mathrm{ml}$ de iodopovidona a $0,2 \%, 0,4 \%$ ou $0,5 \% ; 15 \mathrm{ml}$ de clorexidina a $0,12 \%$; ou $15 \mathrm{ml}$ de enxaguante bucal à base de cloreto de cetilpiridínio a $0,05 \% .{ }^{13}$

\section{Peróxido de hidrogênio}

$\mathrm{O}$ peróxido de hidrogênio $\left(\mathrm{H}_{2} \mathrm{O}_{2}\right)$ tem sido usado na Odontologia há mais de 100 anos para promover a redução da placa bacteriana e microrganismos relacionados à doença periodontal e auxiliar no processo de cicatrização tecidual. É um forte agente oxidante, incolor, inodoro, hidrossolúvel e relativamente instável que demonstra ação antimicrobiana mediante sua decomposição e liberação de oxigênio. Sua eficiência é dependente da concentração, tempo de exposição e presença de materiais orgânicos e inorgânicos no meio. ${ }^{14,15}$

Pertence a um grupo de moléculas denominadas espécies reativas de oxigênio, que inclui uma série de espécies que contêm um ou mais elétrons não pareados (radicais), como o ânion superóxido $\left(\mathrm{O}_{2^{-}} \bullet\right)$, radical hidroxila $(\mathrm{OH} \bullet)$, radical peroxila $\left(\mathrm{RO}_{2} \bullet\right)$ e radical alcoxila $(\mathrm{RO} \bullet)$. O espectro de ação do $\mathrm{H}_{2} \mathrm{O}_{2}$ inclui uma ampla gama de microrganismos, incluindo bactérias grampositivas e gram-negativas, leveduras, fungos, vírus e esporos. O peróxido de hidrogênio é capaz de retardar a divisão celular e danificar células por meio de diferentes mecanismos, comprometendo várias funções celulares e provocando a morte celular. Ao ser convertido no altamente reativo radical hidroxila, causa danos ao DNA, RNA, proteínas, lipídios e membranas celulares nuclear e mitocondrial. ${ }^{15}$

$\mathrm{O}_{2} \mathrm{O}_{2}$ pode permear rapidamente as células e inibir a síntese de ATP (trifosfato de adenosina). Ao difundir-se através das membranas lipídicas e entrar na célula, reage com ferro, cobre e demais metais de transição para gerar o radical hidroxila $(\mathrm{OH} \bullet)$ e outros agentes oxidantes. Essas substâncias iniciam reações em cadeia de peroxidação de lipídios (degradação oxidativa), causando decomposição dos fosfolipídios das membranas celulares, resultando em danos às membranas lisossomais e vazamento de seus conteúdos destrutivos. ${ }^{15}$

A ação antimicrobiana também ocorre por danificação do DNA. A formação de quebras de fita de DNA leva a ativação da poli (ADP-ribose) polimerase que, por sua vez, causa o esgotamento de NAD (nicotinamida adenina dinucleotídeo) e ATP, seguido por influxo de íons de cálcio e, eventualmente, lise celular. ${ }^{14,15}$

Diversos vírus também são sensíveis ao $\mathrm{H}_{2} \mathrm{O}_{2}$, incluindo o vírus da gripe suína (Influenzavirus A subtipo $\mathrm{H} 1 \mathrm{~N} 1$ ), vírus da rubéola (Rubella virus), vírus da raiva (Rabies virus) e outros. ${ }^{16}$ Apesar de não haver ensaios clínicos randomizados, ou estudos clínicos observacionais sobre o efeito preventivo, ou curativo do peróxido de hidrogênio contra infecções virais, estudos imunológicos 
in vitro apontam que a aplicação de peróxido de hidrogênio nas células epiteliais do nariz, garganta eboca pode ser eficaz contra diversos vírus, incluindo espécies de coronavírus. Devido a essas observações e ao fato de o SARS-CoV-2 ser vulnerável à oxidação, é recomendado a realização de bochechos com soluções que contenham agentes oxidativos, como o peróxido de hidrogênio a 1,5\%, $2 \%$ ou $3 \%$, durante 1 minuto, para redução da carga viral. ${ }^{1,13,16}$

Em contrapartida, um estudo in vitro realizado por Bidra et al. ${ }^{18}$ observaram que as soluções de peróxido de hidrogênio nas concentrações recomendadas para enxágue oral de $1,5 \%$ e $3 \%$ mostraram um efeito virucida mínimo em relação ao SARS-CoV-2, após tempo de contato de até 30 segundos.

O contato direto e prolongado dos tecidos moles o com peróxido de hidrogênio a $3 \%$, ou a exposição a altas concentrações por breves períodos pode causar inflamação, hiperplasia, descamação ou irritação em pele e mucosa, com manifestação de queimação, eritema e edema. No entanto, quando utilizado em concentrações mais baixas, as alterações são menos evidentes, mesmo com exposição contínua. ${ }^{16}$

De modo geral, a realização de bochechos com $\mathrm{H}_{2} \mathrm{O}_{2}$ a $3 \%$, ou em concentrações menores, mesmo por períodos prolongados, é segura e benéfica na redução dos níveis de microrganismos presentes no ambiente oral. ${ }^{14,15}$

\section{Clorexidina}

A clorexidina é uma solução antisséptica usada desde 1954 e, atualmente, disponível para comercialização nas concentrações de $0,5 \%$ a $4 \%$. Pode ser encontrada na composição de enxaguantes bucais, aerossóis/sprays $(0,12-0,2 \%)$, géis $(0,12-$ $1 \%)$, vernizes dentais $(1 \%, 10 \%, 40 \%)$, além de pastas de dente, géis para limpeza de dentes e fios dentais. ${ }^{18}$

A clorexidina é usada na assepsia extrabucal ( $2 \%$ ou $4 \%$ ) e intrabucal $(0,12 \%$ ou $0,2 \%)$, para desinfecção de pele, mucosas e descontaminação orofaríngea; na redução dos índices e inibição da formação de placa bacteriana supragengival e subgengival ( $0,02 \%$ ou $0,2 \%)$; no tratamento de gengivite e periodontite; na prevenção de cárie dentária; na forma de gel (2\%) como auxiliar na instrumentação e desinfecção do sistema de canais radiculares, durante o tratamento endodôntico; na prevenção de alveolite pósexodontias e no tratamento da halitose. ${ }^{19}$

É uma biguanida catiônica $\left(\mathrm{C}_{22} \mathrm{H}_{30} \mathrm{Cl}_{2} \mathrm{~N}_{10}\right)$ composta por dois anéis 4-clorofenil e dois grupos biguanida conectados por uma cadeia de hexametileno central. Caracteriza-se como uma base forte praticamente insolúvel em água. No entanto, os sais de clorexidina (diacetato de clorexidina, dicloridrato de clorexidina e digluconato de clorexidina) são mais estáveis e hidrossolúveis, sendo empregados na formulação de soluções antissépticas. O sal de clorexidina mais comumente utilizado em formulações para uso bucal é o digluconato de clorexidina (gliconato de clorexidina ou gluconato de clorexidina), de fórmula química $\mathrm{C}_{34} \mathrm{H}_{54} \mathrm{Cl}_{2} \mathrm{~N}_{10} \mathrm{O}_{14}$. Solúvel em água e em pH fisiológico, tem a capacidade de dissociarse em moléculas carregadas positivamente e, quando em solução aquosa, apresenta-se como um líquido incolor ou amarelo claro. ${ }^{19}$

A clorexidina exibe baixa irritabilidade e demonstra substantividade, ou seja, a capacidade de retenção às superfícies dentais e mucosas, permitindo sua liberação gradual nos fluidos orais e permanência na cavidade bucal por um período prolongado. Sua atividade é dependente do $\mathrm{pH}$ do ambiente, sendo maior em $\mathrm{pH}$ alcalino. 3,19

A atividade antimicrobiana da 
clorexidina é reduzida na presença de soro, sangue, pus e outras matérias orgânicas, saponáceos e compostos aniônicos. Alguns ingredientes presentes em cremes dentais, como o tensoativo aniônico lauril sulfato de sódio (LSS), têm a capacidade de neutralizar sua ação.3,19

A clorexidina liga-se nãoespecificamente aos fosfolipídios carregados negativamente presentes na membrana celular de bactérias e outros microrganismos, altera a permeabilidade da membrana e pode provocar a morte celular. Sua ação é dose dependente, em baixas concentrações (0,02\% a 0,06\%) apresenta atividade bacteriostática, enquanto em concentrações mais altas (superiores a 0,12\%) atua como bactericida. Em baixas concentrações, afeta a integridade da membrana e provoca mudança no equilíbrio do estado osmótico da célula microbiana. Isso leva à liberação e perda de íons de potássio, fósforo e outras moléculas de baixo peso molecular. Essa condição é reversível quando ocorre a remoção do composto antisséptico. ${ }^{18,19}$

Quando em altas concentrações, a clorexidina causa morte celular por citólise. Os danos à membrana plasmática levam a mudanças na estrutura proteica da célula, precipitação de proteínas citoplasmáticas, perda do conteúdo celular, com liberação dos principais componentes intracelulares, incluindo nucleotídeos, e culmina com a morte celular. ${ }^{18}$

A clorexidina age contra bactérias gram-positivas e gram-negativas, bactérias aeróbias, anaeróbias e anaeróbias facultativas, fungos, leveduras e vírus envelopados. Entre esses vírus estão: Herpes simplex virus 1 (HSV1), vírus da imunodeficiência humana (HIV), Hepatitis B virus (HBV), Influenzavirus A, Human parainfluenza virus ze Cytomegalovirus (CMV). Segundo estudo de Kawana et al. ${ }^{20}$ os vírus da rubéola (Rubella virus), sarampo (Measles morbillivirus), caxumba (Mumps virus) também se mostraram sensíveis à clorexidina. Essa substância, no entanto, não atua contra microrganismos álcool-ácido resistentes, esporos bacterianos e vírus não envelopados, como Human papillomavirus (HPV), Hepatitis $A$ virus (HAV), adenovírus e enterovírus (ex.: poliovírus). ${ }^{18,19,20}$

Pesquisas in vitro evidenciaram a efetividade da clorexidina na inativação imediata do HIV (com concentrações iguais ou superiores a $0,2 \%$ ), sua atividade virucida contra HSV-1, CMV, Influenza A, parainfluenza e HBV (na concentração de 0,12\%) após 5 minutos de exposição. Geralmente, vírus não envelopados apresentaram-se resistentes à clorexidina, pois a atividade virucida desse antisséptico depende da sua interação com o envelope lipídico viral. No entanto, os rotavírus são uma exceção, visto que a clorexidina demonstra ação eficaz contra esse gênero viral ao interagir com glicoproteínas de presentes no capsídeo viral. Além disso, nem todos os vírus envelopados apresentaram a mesma suscetibilidade à clorexidina, o que pode ser explicado pelas sutis diferenças químicas e físicas dos envelopes lipídicos virais. ${ }^{21}$

Há poucos estudos a respeito da ação da clorexidina contra coronavírus, e a maioria avalia somente a ação da clorexidina na esterilização de superfícies inertes ao invés de tecidos vivos. Essa pesquisa aponta que coronavírus, apesar de apresentar envelope lipídico, demonstra sensibilidade à clorexidina apenas quando esta é usada em combinação com outros compostos, como etanol ou cetrimida. ${ }^{22}$

Segundo as Diretrizes para o Diagnóstico e Tratamento da Nova Pneumonia por Coronavírus, divulgada pela Comissão Nacional de Saúde da República Popular da China, os bochechos com clorexidina podem não ser efetivos contra a redução da carga viral do SARS-CoV-2. Contudo, o 
manual de orientações de biossegurança para adequações técnicas em tempos de COVID-19, divulgado pelo Conselho Regional de Odontologia de São Paulo (CRO/SP) em julho de 2020, orienta que o paciente deve ser instruído a realizar bochechos com uma solução de digluconato de clorexidina a $0,12 \%$ antes da entrada na sala de procedimento. ${ }^{1,23}$

Em um estudo recente de Yoon et al., ${ }^{10}$ a avaliação de fluidos corporais por 9 dias de 2 pacientes testados positivo para COVID-19 mostrou que o bochecho com clorexidina foi efetivo na redução da carga viral na saliva por um curto período de tempo (até 2 horas após o uso), tornando a aumentar após 2 a 4 horas. A supressão viral por 2 horas, após o uso de $15 \mathrm{ml}$ de clorexidina a $0,12 \%$, sugere que esse antisséptico seria benéfico para o controle da transmissão da SARS-CoV-2. No entanto, o estudo apresenta limitações, devido ao reduzido número de pacientes participantes da pesquisa, e a não inclusão de um grupo de controle. A realização de mais estudos in vivo, em larga escala e incluindo grupos de controle é necessária para determinar se o uso da clorexidina é eficaz na inativação do SARSCoV-2 e prevenção de sua transmissão.

O uso prolongado de clorexidina na maioria das vezes ocasiona descoloração dos dentes, língua, restaurações de resina composta e restaurações de ionômero de vidro. Pode provocar irritação da mucosa oral e alteração do paladar temporárias, que desaparecem após término da terapia.3,19

\section{lodopovidona}

O iodo é empregado há mais de 150 anos na antissepsia de mucosa, no tratamento de queimaduras, feridas e infecções de pele. Os iodóforos são uma combinação de iodo com um agente solubilizante ou veículo, que resulta em um reservatório de liberação contínua de pequenas quantidades de iodo ativo livre em solução aquosa. ${ }^{24}$

O iodóforo mais conhecido e utilizado é a iodopovidona (polivinilpirrolidona-iodo ou PVP-I). Esse composto estável e ativo foi desenvolvido em 1955 nos Laboratórios de Toxicologia Industrial na Filadélfia por H. A. Shelanski e M. V. Shelanski, com o objetivo de produzir um complexo antimicrobiano de iodo que fosse menos tóxico que a tintura de iodo. Atualmente, ainda é bastante utilizado como antisséptico cutâneo pré-cirúrgico e como enxaguante bucal. Consiste em um complexo formado pela reação do iodo com o veículo polivinilpirrolidona (povidona ou PVP), que quando em contato com água libera o iodo progressivamente. ${ }^{24,25}$

A solução aquosa de iodopovidona a $10 \%$ com $1 \%$ de iodo ativo é a mais usada para antissepsia de pele e superfícies mucosas em cirurgias, tratamento de feridas, prevenção e controle de infecções bacterianas, fúngicas e virais. A solução de PVP-I a 1\% é empregada no tratamento de mucosite, na profilaxia de infecções orofaríngeas e em aplicações oftálmicas (de $1 \%$ a $5 \%$ ). Já nas concentrações de $0,2 \%$ a $1 \%$, a iodopovidona pode ser utilizada como antisséptico bucal. ${ }^{13,25,26}$

A ação antimicrobiana da PVP-I ocorre após o iodo livre $\left(I_{2}\right)$ dissociar-se da polivinilpirrolidona. Em sua forma livre, o iodo oxidafosfolipídios daparedecelulareorganelas intracelulares, penetrando rapidamente nos microrganismos, provocando a quebra de proteínas, oxidação das estruturas dos ácidos nucléicos e consequente morte microbiana. $O$ espectro de ação compreende bactérias grampositivas, gram-negativas, micobactérias, fungos, protozoários, vírus envelopados e não-envelopados. A iodopovidona não atua contra esporos bacterianos. ${ }^{24,25,26}$

Soluções de PVP-I nas concentrações de $0,23 \%$ a $7 \%$ demonstram atividade virucida altamente eficaz contra uma grande variedade de vírus, incluindo espécies de coronavírus 
(SARS-CoV e MERS-CoV). ${ }^{28}$ A iodopovidona é eficaz na inativação de vírus envelopados (Herpes simplex virus, Influenzavirus A, HIV, Rubella virus, Measles morbillivirus, Mumps virus) e não-envelopados (como adenovírus, rotavírus, poliovírus tipos 1 e 3, rinovírus, (oxsackievirus), apresentando um espectro de atividade antiviral mais amplo que o da clorexidina e de outros antissépticos. ${ }^{20}$

A atividade virucida da PVP-I contra MERS-CoV foi avaliada por Eggers, Eickmann e Zorn. ${ }^{28}$ Foram testadas in vitro formulações nas concentrações de $1 \%, 4 \%$ e $7,5 \%$ e concluiuse que soluções de iodopovidona de $1 \%$ a $7,5 \%$ podem reduzir a titulação viral em mais de 99,99\% em 15 segundos após a aplicação do produto. A eficácia na inativação do SARSCoV e MERS-CoV também foi observada 15 segundos, após o uso de PVP-I diluída na proporção 1:30 (com 0,23\% de iodo ativo). ${ }^{28}$

Bidra et al. ${ }^{17}$ realizaram um estudo in vitro comparando a capacidade de inativação do SARS-CoV-2 pelo peróxido de hidrogênio e iodopovidona em diferentes concentrações e tempos de contato. $O$ vírus foi completamente inativado pela PVP-I nas concentrações de $0,5 \%$ a $1,5 \%$ em apenas 15 segundos, enquanto as soluções de peróxido de hidrogênio apresentaram efeito virucida mínimo, mesmo após 30 segundos. Baseado nesses resultados, foi concluído que o bochecho pré-procedimento com PVP-I diluída na faixa de $0,5 \%$ a 1,5\% é uma melhor escolha em comparação ao peróxido de hidrogênio, havendo a necessidade de ensaios clínicos randomizados para que seja possível determinar o protocolo mais adequado para a execução do enxágue bucal pré-procedimento no atendimento odontológico de rotina.

Em um estudo posterior de Bidra et al. $^{29}$ que investigou a concentração de PVP-I e o tempo de contato ideais para a eliminação do SARS-CoV-2, chegou-se à conclusão que as soluções antissépticas de iodopovidona inativaram rapidamente o vírus SARS-CoV-2 in vitro. Todas as formulações testadas, nas concentrações de 0,5\%, $1 \%$ e $1,5 \%$, conseguiram inativar completamente o SARS-CoV-2 após 15 segundos de contato.

Em um estudo clínico de Lamas et al.30 uma amostra de saliva foi coletada de 4 pacientes com COVID-19. Após o bochecho com $15 \mathrm{ml}$ de iodopovidona a $1 \%$, durante 1 minuto, amostras em série de saliva foram coletadas 5 minutos, 1 hora, 2 horas e 3 horas depois. Os resultados preliminares sugerem que um enxágue com PVP-I pode reduzir a carga viral da saliva de SARS-CoV-2 em pacientes com cargas virais mais altas. Contudo, o número reduzido de participantes representou uma limitação da pesquisa.

A PVP-I é segura para uso em cavidade oral nas concentrações de até $5 \%$ e cavidades nasais em concentrações de até $1,25 \%$. É um composto hidrossolúvel, menos alergênico que o iodo, que não provoca irritações em pele ou mucosas, mesmo com uso prolongado, não causa reações locais, ou sistêmicas, quando aplicado topicamente. Não induz a seleção de bactérias resistentes, não altera o paladar e não mancha acentuadamente a pele, sendo facilmente removida em água corrente. Entretanto, não é comercialmente disponível nas concentrações mais baixas para uso como antisséptico bucal.3,26,29 Entre as contraindicações ao uso da iodopovidona estão pacientes com hipersensibilidade ao iodo, doença tireoidiana ativa, em terapia com iodo radioativo, gestantes e lactantes. 3,29 


\title{
CONSIDERAÇÕES FINAIS
}

\author{
Apesar da realização de bochechos pré- \\ procedimento, com soluções antissépticas, \\ ser recomendada como medida de prevenção \\ contra a COVID-19 por organizações e \\ associações de referência em saúde, não há \\ evidência científica suficiente baseada em \\ estudos clínicos que comprovem a efetividade \\ do uso dos antissépticos bucais para redução \\ da carga viral, ou prevenção de transmissão
}

\begin{abstract}
do SARS-CoV-2. Dessa forma, a realização de estudos clínicos randomizados se faz necessária. Além disso, também é importante investigar a conduta dos cirurgiões-dentistas, quanto à sua atuação e aceitabilidade da adoção das recomendações de biossegurança no contexto de pandemia da COVID-19, de forma a caracterizar os atendimentos atuais e nortear uma melhor conduta clínica.
\end{abstract}

\section{PREPROCEDURAL ANTISEPTIC MOUNTHRINSE AS PREVENTION TO SARS-COV-2 IN DENTISTRY: INTEGRATIVE REVIEW}

\begin{abstract}
SARS-CoV-2 and the COVID-19 pandemic highlighted the biological risks to which the dental team is exposed and the need to adopt biosafety measures to reduce the possibility of contamination in the dental environment. One of the recommendations to reduce the risk of viral transmission is the use of oral antiseptics by patients before dental care. This literature review proposes to analyze the available information regarding the use of mouth rinses in Dentistry and the possible activity of these solutions against the novel coronavirus. For this review, scientific publications were selected from the electronic databases Science Direct, Google Scholar, Scielo and PubMed, covering the themes SARSCoV-2 and oral antiseptics recommended for pre-procedural mouthwash. The results of the review show that oral antiseptics are used in dentistry to reduce the amount of microorganisms, treatment of gum and periodontal diseases, plaque control and prophylaxis against infections. There are no yet clinical studies that prove the effectiveness of pre-procedure mouthwashes in reducing viral load or preventing transmission of SARS-CoV-2. However, pre-procedural mouthwash rinsing is recommended by leading health organizations and associations. In view of this, it is necessary to carry out randomized clinical studies that prove the effectiveness of the use of oral antiseptics against SARS-CoV-2.
\end{abstract}

KEYWORDS: Dentistry. SARS-CoV-2. Hydrogen Peroxide. Chlorhexidine. Povidone-lodine. 


\section{REFERÊNCIAS}

1. Peng X, Xu X., Li Y., Cheng L., Zhou X., Ren B. Transmission routes of 2019-nCoV and controls in dental practice. Int J Oral Sci. 2020; 12 (9): 1-6.

2. Harrel SK., Molinari J. Aerosols and splatter in dentistry: a brief review of the literature and infection control implications. J Am Dent Assoc. 2004; 135(4): 429-37.

3. Slots J. Selection of antimicrobial agents in periodontal therapy. J Periodontal Res. 2002; 37(5): 389-98.

4. Organização Mundial daSaúde.Considerations for the provision of essential oral health services in the context of COVID-19. [Internet]; 2020. [citado em 2020 set. 01]. Disponível em: https:// www.who.int/publications/i/item/who-2019nCoV-oral-health-2020.1.

5. Associação Dental Americana. ADA interim guidance for minimizing risk of COVID-19 transmission. [Internet]; 2020. [citado em 2020 ago. 29]. Disponível em: https://www.kavo.com/ en-us/resource-center/ada-interim-guidanceminimizing-risk-covid-19-transmission.

6. Centro de Controle e Prevenção de Doenças. Guidance for Dental Settings: Interim infection prevention and control guidance for dental settingsduringtheCOVID-19response.[Internet]; 2020. [citado em 2020 set. 01]. Disponível em: https://www.cdc.gov/coronavirus/2019-ncov/ hcp/dental-settings.html.

7. Conselho Federal de Odontologia (Brasil). Recomendações AMIB/CFO para enfrentamento da COVID-19 na Odontologia. [Internet]; 2020. [citado em 2020 set. 09]. Disponível em: ttp://www.crosp.org.br/uploads/arquivo/ d45f45bec26af5e60711423292623321.pdf.

8. Organização Mundial da Saúde. Timeline: WHO's COVID-19 response. [Internet]; 2020. [citado em 2020 out. 02]. Disponível em: https:// www.who.int/emergencies/diseases/novelcoronavirus-2019/interactive-timeline.

9. Lu R., Zhao X., Li J., Niu P., Yang B, Wu H., et al. Genomic characterisation and epidemiology of 2019 novel coronavirus: implications for virus origins and receptor binding. Lacet. 2020; 392(10224): 565-74.

10. Yoon JG., Yoon J., Song JY., Yoon SY. Lim CS., Seong H., et al. Clinical significance of a high SARS-CoV-2 viral load in the saliva. J Korean Med Sci. 2020; 35(20) e159: 1-6.

11. Sungnak W., Huang N., Bécavin C., Berg M., Queen R, Litvinukova M., et al. SARS-CoV-2 entry factors are highly expressed in nasal epithelial cells together with innate immune genes. Nat Med. 2020; 26: 681-87.

12. Organização Mundial da Saúde. WHO Coronavirus Disease (COVID-19) Dashboard. [Internet]; 2020. [citado em 2020 dez. 03]. Disponível em: https://covid19.who.int/. Acesso em: 03 dez. 2020.

13. Vergara-Buenaventura A., Castro-Ruiz C. Use of mouthwashes against COVID-19 in dentistry. Br J Oral Maxillofac Surg. 2002; 58(8): 924-27.

14. Marshall MV, Cancro LP, Fischman SL. Hydrogen peroxide: a review of its use in dentistry. J Periodontol. 1995; 66 (9): 786-96.

15. Walsh $L$. Safety issues relating to the use of hydrogen peroxide in dentistry. Aust Dent J. 2000; 45(4): 257-89.

16. Caruso AA., Del Prete A., Lazzarino Al. Hydrogen peroxide and viral infections: $A$ literature review with research hypothesis definition in relation to the current covid-19 pandemic. Med Hypoteses. 2000; 144: 1-3. 
17. Bidra AS., Pelletier JS., Westover JB., Frank S., Brown SM., Tessema B. Comparison of in vitro inactivation of SARS CoV-2 with hydrogen peroxide and povidone-iodine. J Prosthodont. 2020; 29(7): 599-03.

18. Milstone AM., Passareti CL., Perl TM. Chlorhexidine: expanding the armamentarium for infection control and prevention. Clin Infect Dis. 2008; 46 (2): 274-81.

19. Karpiński TM., Szkaradkiewicz AK. Chlorhexidine - pharmaco-biological activity and application. Eur Rev Med Pharmacol Sci. 2015; 19(7): 1321-26.

20. Kawana R., Kitamura T., Nakagomi O., Matsumoto I., Arita M., Yoshihara N., et al. Inactivation of human viruses by povidoneiodine in comparison with other antiseptics. Dermatology. 1997; 195 (2 supl): 29-35.

21. Bernstein D., Schiff G., Echler G., Prince A., Feller M., Briner W. In vitro virucidal effectiveness of a $0.12 \%$-chlorhexidine gluconate mouthrinse. J Dent Res. 1999; 69(3): 874-76.

22. Geller C., Varbanov M., Duval RE. Human coronaviruses: insights into environmental resistance and its influence on the development of new antiseptic strategies. Viruses. 2012; 4(11): 3044-68.

23. Conselho Regional de Odontologia de São Paulo (São Paulo). Orientações de biossegurança: Adequações técnicas em tempos de covid-19. [Internet]; 2020. [citado em 2020 set. 25]. Disponível em: http://www.crosp.org.br/uploads/ paginas/38f65fd62bd4e5e56b16e859ada6c751. pdf.

24. Centro de Controle e Prevenção de Doenças. Chemical Disinfectants: Guideline for Disinfection and Sterilization in Healthcare Facilities (2008). [Internet]; 2016. [citado em 2020 set. 01]. Disponível em: https://www. cdc.gov/infectioncontrol/pdf/guidelines/ disinfection-guidelines-H.pdf.

25. Kirk-Bayley J., Challacombe SJ., Sunkaraneni VS. The use of povidone iodine nasal spray and mouthwash during the current COVID-19 pandemic may protect healthcare workers and reduce cross infection. SSRN Electron J. 2020; (3563092): 1-10.

26. Eggers M., Koburger-Janssen T., Eickmann M., Zorn J. In vitro bactericidal and virucidal efficacy of povidone-iodine gargle/mouthwash against respiratory and oral tract pathogens. Infect Dis Ther. 2018; 7(2): 249-59.

27. Parhar HS., Tasche K., Brody RM., Weinstein GS., O'Malley Jr W., Shanti RM., et al. Topical preparations to reduce SARS-CoV-2 aerosolization in head and neck mucosal surgery. Head \& Neck. 2020; 42(6): 1268-72.

28. Eggers M., Eickmann M., Zorn J. Rapid and effective virucidal activity of povidone-iodine products against Middle East respiratory syndrome coronavirus (MERS-CoV) and modified Vaccinia Virus Ankara (MVA). Infect Dis Ther. 2015; 4(4): 491-01.

29. Bidra AS., Pelletier JS., Westover JB., Frank S., Brown SM., Tessema B. Rapid in-vitro inactivation of severe acute respiratory syndrome coronavirus 2 (SARS-CoV-2) using povidoneiodine oral antiseptic rinse. J Prosthodont. 2020; 29(6): 529-33.

30. Lamas LM., Dios PD., Rodríguez MTP., Pérez VDC., Alvargonzalez JJC., Domínguez AML., et al. Is povidone iodine mouthwash effective against SARS-CoV-2? First in vivo tests. 2020; 00: 1-4. 